\title{
The Interaction between GSTT1, GSTM1, and GSTP1 Ile105Val Gene Polymorphisms and Environmental Risk Factors in Premalignant Gastric Lesions Risk
}

\author{
Anca Negovan, ${ }^{1}$ Mihaela Iancu, ${ }^{2}$ Valeriu Moldovan, ${ }^{1}$ \\ Simona Mocan, ${ }^{3}$ and Claudia Banescu ${ }^{1,4}$ \\ ${ }^{1}$ University of Medicine and Pharmacy, Tirgu Mureș, Gheorghe Marinescu 38, 540139 Mures, Romania \\ ${ }^{2}$ University of Medicine and Pharmacy "Iuliu Hațieganu" Cluj-Napoca, 8 Victor Babeş, 400012 Cluj-Napoca, Romania \\ ${ }^{3}$ Emergency County Hospital, Tirgu Mureş, Gheorghe Marinescu 50, 540136 Mures, Romania \\ ${ }^{4}$ Center for Advanced Medical and Pharmaceutical Research, University of Medicine and Pharmacy, Tirgu Mures, \\ Gheorghe Marinescu 38, 540139 Mures, Romania
}

Correspondence should be addressed to Mihaela Iancu; mmihaela.iancu@yahoo.com

Received 4 October 2016; Revised 16 November 2016; Accepted 20 November 2016; Published 15 January 2017

Academic Editor: Janusz Blasiak

Copyright (C) 2017 Anca Negovan et al. This is an open access article distributed under the Creative Commons Attribution License, which permits unrestricted use, distribution, and reproduction in any medium, provided the original work is properly cited.

\begin{abstract}
The study investigated the possible influence of GSTM1, GSTT1, and GSTP1 gene polymorphisms as predisposing factors for premalignant gastric lesions as well as their interaction with $H$. pylori infection, gastrotoxic drugs, smoking, and alcohol consumption. In this study, 270 patients with a complet set of gastric biopsies and successfully genotyped were finally included. The GSTM1 gene polymorphism had significant contribution in mild/severe endoscopic lesions $(p=0.01)$ as well as in premalignant lesions $(p=0.01)$. The GSTM1 null genotype increased the risk for mucosal defects in H. pylori-negative patients (OR $=2.27,95 \% \mathrm{CI}$ : $1.20-4.37)$ and the risk for premalignant lesions in patients with no alcohol consumption (OR = 2.13, 95\% CI: 1.19-3.83). The GSTT1 deleted polymorphism did not significantly increase the risk for premalignant lesions in the absence of gastrotoxic drugs $(\mathrm{OR}=1.82$, 95\% CI: 0.72-4.74). The combined GSTT1T1 and GSTM1 null polymorphisms were borderline correlated with an increased risk for premalignant lesions $(\mathrm{OR}=1.72,95 \% \mathrm{CI}: 1.00-2.97)$. The wild-type GSTP1 Ile/Ile genotype versus the variant genotypes Ile/Val + $\mathrm{Val} / \mathrm{Val}$ was significantly associated with a decreased risk of gastric atrophy/intestinal metaplasia $(\mathrm{OR}=0.60,95 \% \mathrm{CI}: 0.37-0.98)$. In conclusion, the GSTM1 and GSTT1 null genotypes increased the risk for premalignant and endoscopic gastric lesions, modulated by H. pylori, alcohol, or gastrotoxic drug consumption, while the presence of the GSTP1Val allele seemed to reduce the risk for premalignant lesions.
\end{abstract}

\section{Introduction}

It is widely accepted today that gastric carcinogenesis is a multistep and multifactorial process, influenced by interactions between the host's genetic susceptibility and environmental factors. For the intestinal type of gastric cancer the role of Helicobacter pylori ( $H$. pylori) infection and histopathology of the precancerous lesions (chronic gastritis, gastric atrophy (GA), intestinal metaplasia (IM), and epithelial dysplasia (ED)) have long been accepted $[1,2]$. An important role seems to play the interaction between $H$. pylori (and its virulence) infection as a triggering factor and the host's genetic susceptibility [3]. Although numerous studies have investigated genetic polymorphisms in gastric cancer, little has been performed related to precancerous gastric lesions.

Glutathione S-transferases (GSTs) are the most important enzymes of the phase II metabolizing xenobiotic pathway, which detoxifies several cytotoxic compounds [4]. They are involved in the metabolism of carcinogens, drugs, and reactive oxygen species (ROS) playing a protective role against the oxidative damage of DNA [5]. They have been grouped into at least seven classes called $\alpha$ (alpha), $\mu$ (mu), $\pi$ (pi), $\sigma$ (sigma), $\omega$ (omega), $\theta$ (theta), and $\zeta$ (zeta) [68]. Glutathione S-transferase T1 (GSTT1) and glutathione 
S-transferase M1 (GSTM1) are members of the $\theta$ and $\mu$ classes, respectively, and have been shown to be polymorphic. The common variant of GSTM1 and GSTT1 genes is the homozygous deletion (null genotype) which leads to reduced enzyme activity and increased risk for various diseases, including esophageal, gastric, or colon cancer $[9,10]$. For glutathione S-transferase P1 (GSTP1) the single-nucleotide polymorphisms (SNPs) in the GSTP1 gene, resulting in amino acid substitutions at codons 105 ( $\mathrm{Ile} \rightarrow \mathrm{Val})$ and $114(\mathrm{Val} \rightarrow \mathrm{Ala})$, have been associated with diminished GST enzyme activity $[8,9,11]$. In numerous studies the GSTM1, GSTT1, and GSTP1 gene polymorphisms have been investigated for their possible role in risk occurrence of various diseases, including gastric cancer [5]. The roles of variant GST polymorphisms were questioned especially in interaction with environmental recognized risk factors for gastric cancer (H. pylori infection, smoking, alcohol consumption, or salt intake) [12-16]. At present, the studies' results are inconclusive and there are no defined genetic markers having important roles in the progression thorough the carcinogenesis cascade [3, 12-18].

The objectives of our study were (i) to investigate the influence of GSTM1, GSTT1, and GSTP1 Ile105Val gene polymorphisms on the risk of gastric precancerous lesions and (ii) to test the possible interaction effect between genetic and environmental factors $(H$. pylori current infection, smoking, alcohol, and drug consumption) in histologic and endoscopic gastric lesions in Romanian population.

\section{Materials and Method}

2.1. Subjects. Consecutive patients referred for upper digestive endoscopies (UDE) to the 3rd Medical Clinic of the Tirgu Mures Emergency County Hospital, Romania, were screened for study inclusion. Patients were examined for dyspeptic symptoms, anemia, or screened for gastrointestinal bleeding risk (before major cardiovascular surgery or before the start of antithrombotic therapies). Clinical and demographical data were collected by structured interview, clinical examination, and reviewing of medical records. We considered, as drinkers, patients consuming at least 10 units $(10 \mathrm{~mL})$ of pure alcohol weekly and nondrinkers patients consuming any amount of alcohol below this level. Patients smoking more than 5 cigarettes/day including quitters during the past 5 years were considered as smokers. We recorded the digestive symptoms, namely, upper abdominal pain, heartburn, regurgitation, nausea, vomiting, and early satiety. We considered gastrotoxic drug exposure the nonsteroidal anti-inflammatory drugs (NSAIDs) consumption as regular daily doses in patients with arthritis or other inflammatory disorders who needed chronic therapy (more than six months). Long-term antiplatelet therapy (low-dose aspirin $75-325 \mathrm{mg}$ /day; clopidogrel $75 \mathrm{mg} /$ day more than 6 months) was also considered gastrotoxic medication. We excluded patients with acute bleeding episodes, previous therapy for eradication of $H$. pylori infection, gastric surgery, gastric or esophageal cancer, and esophageal varices, patients with severe medical conditions (cancer, cirrhosis, severe heart or renal failure, etc.), and patients with lacking data (biopsies, social habits, and drug exposure).
The Ethical Committee of the University of Medicine and Pharmacy of Tirgu Mures, Romania, approved the study and a written informed consent was obtained from all subjects included.

2.2. Genotyping. Blood samples were used for rapid extraction of genomic DNA. GSTM1 and GSTT1 gene polymorphisms were analyzed by the use of multiplex polymerase chain reaction as described previously [19]. The GSTP1 Ile105Val gene polymorphism was investigated by PCR-RFLP (polymerase chain reaction and restriction fragment length polymorphism) method as previously described [20].

Genotyping was successfully performed in 373 cases. Genotype frequencies of GSTP1 gene polymorphisms did not deviate significantly from the expected frequencies of HardyWeinberg equilibrium on each subgroup $(p=0.23$ in group without endoscopic lesions, resp., $p=0.964$ in group without premalignant lesions).

Finally, there were 270 patients included in the analysis; controls were frequency-matched with the cases by age \pm 5 years.

2.3. Endoscopy. Endoscopy was carried out in every patient by an endoscopist blinded to drug exposure and symptoms. We described mucosal lesions as erythema, petechiae, erosions, or ulcers. Petechiae were defined as hemorrhagic areas with no mucosal defect and erosions as mucosal defects smaller than $5 \mathrm{~mm}$. Defects larger than $5 \mathrm{~mm}$ in diameter, extended into the deeper layers of the gastric or duodenal wall, were defined as ulcer. Endoscopic mucosal lesions were classified as mild if only erythema, petechiae, or less than two erosions were observed on endoscopic examination. We considered severe endoscopic lesions the presence of more than three erosions or ulcer in the gastroduodenal mucosa.

Two biopsy specimens from the antrum and two from the corpus (from the lesser and the greater curvature) were obtained for routine histology in every patient. Two pathologists also blinded to patient drug exposure and symptoms examined them.

2.4. Histology. Biopsy specimens were fixed in $10 \%$ buffered formalin, routinely processed, embedded in paraffin, and stained with hematoxylin-eosin, PAS-alcian blue, and Giemsa. H. pylori infection was considered negative if $H$. pylori were absent from all biopsy sites and positive if at least one histology test was positive. The degrees of mucosal chronic inflammation, activity, $H$. pylori infection, glandular atrophy, and intestinal metaplasia were classified into 4 grades according to the Updated Sydney System. It has long been recognized that intestinal metaplasia (IM) is heterogeneous, and several classifications have been proposed. We considered complete metaplasia when the epithelium resembles the small intestinal phenotype with eosinophilic enterocytes displaying a well-defined brush border and well-formed goblet cells and incomplete metaplasia the presence of a colonic epithelium phenotype with multiple, irregular mucin droplets of variable size in the cytoplasm and absence of a brush border. We also evaluated dysplasia according to the modified Vienna classification, but patients with dysplasia or neoplasia were 
TABLE 1: The distribution of H. pylori infection, gastrotoxic medication, alcohol consumption, and smoking in the studied group.

\begin{tabular}{|c|c|c|c|c|c|c|}
\hline & $\begin{array}{c}\text { Without } \\
\text { endoscopic lesions } \\
(n=169) \\
\end{array}$ & $\begin{array}{c}\text { Mild or severe } \\
\text { endoscopic lesions } \\
(n=101)\end{array}$ & $p$ value $^{*}$ & $\begin{array}{c}\text { Without } \\
\text { premalignant lesions } \\
(n=141)\end{array}$ & $\begin{array}{l}\text { With premalignant } \\
\text { lesions }(n=129)\end{array}$ & $p$ value $^{*}$ \\
\hline Age $($ mean $\pm S D)$ & $65.64 \pm 9.60$ & $66.12 \pm 7.88$ & 0.656 & $65.06 \pm 8.07$ & $66.65 \pm 9.85$ & 0.149 \\
\hline$\leq 60$ & 45 & 23 & 0.480 & 38 & 30 & 0.485 \\
\hline$>60$ & 124 & 78 & & 103 & 99 & \\
\hline \multicolumn{7}{|l|}{ Sex } \\
\hline Female & 95 & 44 & 0.059 & 73 & 66 & 0.920 \\
\hline Male & 74 & 57 & & 68 & 63 & \\
\hline \multicolumn{7}{|l|}{ H. pylori infection } \\
\hline Negative & 119 & 66 & 0.386 & 99 & 86 & 0.531 \\
\hline Positive & 50 & 35 & & 42 & 43 & \\
\hline \multicolumn{7}{|l|}{ Gastrotoxic drugs $^{\mathrm{a}}$} \\
\hline No & 89 & 37 & 0.011 & 64 & 62 & 0.660 \\
\hline Yes & 80 & 64 & & 77 & 67 & \\
\hline \multicolumn{7}{|l|}{ Smoking ${ }^{\mathrm{b}}$} \\
\hline Nonsmoker & 157 & 90 & 0.280 & 136 & 111 & 0.002 \\
\hline Smoker & 12 & 11 & & 5 & 18 & \\
\hline \multicolumn{7}{|l|}{ Alcohol $^{\mathrm{c}}$} \\
\hline No & 129 & 74 & 0.573 & 107 & 96 & 0.780 \\
\hline Yes & 40 & 27 & & 34 & 33 & \\
\hline
\end{tabular}

$\mathrm{SD}=$ standard deviation; ${ }^{\mathrm{a}}$ presence of NSAIDs or antiplatelet therapy; ${ }^{\mathrm{b}}>5$ cigarettes/day including quitters during the past 5 years; ${ }^{\mathrm{c}}$ consumption of $>10$ units/week, ${ }^{*}$ obtained from Student's $t$-test for independent samples or Chi-square test.

excluded. Patients without important inflammation, but with prominent foveolar hyperplasia, fibromuscular replacement of the lamina propria, and congestion of superficial mucosal capillaries, were diagnosed as reactive gastropathy. We did not include patients with autoimmune gastritis or with an incomplete set of biopsies.

2.5. Statistical Analysis. The quantitative variables representing demographic characteristics were expressed as mean \pm standard deviation while studied environmental and gene polymorphisms factors were summarized by absolute and relative frequencies. The differences in distribution of demographic variables and selected gene polymorphisms between cases (mild or sever endoscopic lesions and gastric atrophy or intestinal metaplasia) and controls (without endoscopic lesions and without gastric atrophy) were tested by Student's $t$-test and Chi-square test.

The associations between studied gene polymorphisms and the risk of gastric lesions were tested by logistic regression analysis. The magnitude of association was quantified by the multivariable odds ratio and their $95 \%$ confidence intervals. We evaluated the gene-environment interaction using a multivariable multiplicative model composed by age, sex, environmental, genetic factors, and the interaction term of interest.

The level of statistical significance for all two-sided tests was set to 0.05 .

The advanced environment for statistical computing $\mathrm{R}$ (v.3.3.1, Vienna, Austria) was used for statistical analysis.

\section{Results}

3.1. Description of Sample Selected Characteristics. The study included 270 patients successfully genotyped with a complete set of data. The distribution of demographic and clinical characteristics in the studied group is described in Table 1. The repartition of age values and sex frequency was homogenous in all studied subgroups $(p>0.05)$. There was no significant difference in the distribution of $H$. pylori and alcohol consumption between patients without endoscopic lesions and patients with mild or severe endoscopic lesions $(p>$ 0.05). There was no significant association between these factors and gastric atrophy or intestinal metaplasia $(p>$ $0.05)$. Antiplatelet or NSAIDs consumption was significantly associated with mild or severe endoscopic lesions ( $p=$ $0.011)$. Premalignant lesions were associated with smoking habits $(p=0.002)$, but not with $H$. pylori active infection or alcohol consumption.

3.2. Association between Selected Polymorphisms and Risk of Endoscopic Lesions or Premalignant Gastric Lesions (Gastric Atrophy or Intestinal Metaplasia). There was no significant difference regarding the frequency distribution of GSTP1 Ile105Val, GSTT1, and GSTM1 variant genotypes in patients without endoscopic lesions versus patients with mild or severe endoscopic lesions (49.7 versus 39.6\%, $\chi^{2}(1)=2.60, p=$ 0.130 for GSTP1 Ile105Val; $20.7 \%$ versus $20.8 \%, p=0.987$ for GSTT1; and $46.7 \%$ versus $56.4 \%, \chi^{2}(1)=2.60, p=0.130$ for GSTM1). 
TABLE 2: Effect of the studied gene polymorphisms on the outcome variable.

\begin{tabular}{|c|c|c|c|c|c|c|c|c|}
\hline & \multicolumn{2}{|c|}{$\begin{array}{l}\text { Without endoscopic } \\
\text { lesions versus mild or } \\
\text { severe endoscopic } \\
\text { lesions }(169 / 101)\end{array}$} & $p$ value ${ }^{*}$ & $\begin{array}{c}\text { Adjusted } \mathrm{OR}^{\dagger} \\
{[95 \% \mathrm{CI}]}\end{array}$ & \multicolumn{2}{|c|}{$\begin{array}{c}\text { Without } \\
\text { premalignant lesions } \\
\text { versus with } \\
\text { premalignant lesions } \\
(141 / 129) \\
\end{array}$} & \multirow[t]{2}{*}{$p$ value ${ }^{*}$} & \multirow[t]{2}{*}{$\begin{array}{l}\text { Adjusted } \mathrm{OR}^{\dagger} \\
\quad(95 \% \mathrm{CI})\end{array}$} \\
\hline \multicolumn{7}{|l|}{ GSTP1 Ile105Val } & & \\
\hline Ile/Ile $\mathrm{a}^{\mathrm{a}}$ & 85 & 61 & & & 68 & 78 & & \\
\hline $\mathrm{Ile} / \mathrm{Val}+\mathrm{Val} / \mathrm{Val}$ & 84 & 40 & 0.116 & $0.67[0.4,1.11]$ & 73 & 51 & 0.038 & $0.60[0.37,0.98]$ \\
\hline \multicolumn{9}{|l|}{ GSTT1 } \\
\hline $\mathrm{Tl}^{\mathrm{a}}$ & 134 & 80 & & & 110 & 104 & & \\
\hline Null & 35 & 21 & 0.844 & $0.94[0.50,1.74]$ & 31 & 25 & 0.627 & $0.86[0.47,1.57]$ \\
\hline \multicolumn{9}{|l|}{ GSTM1 } \\
\hline $\mathrm{M1}^{\mathrm{a}}$ & 90 & 44 & & & 77 & 57 & & \\
\hline Null & 79 & 57 & 0.106 & $1.51[0.92,2.52]$ & 64 & 72 & 0.074 & $1.55[0.96,2.53]$ \\
\hline \multicolumn{9}{|l|}{ GSTT1/M1 } \\
\hline T1/M1 & 70 & 33 & & & 60 & 43 & & \\
\hline T1/null & 64 & 47 & 0.115 & $1.58[0.90,2.79]$ & 50 & 61 & 0.050 & $1.72[1.00,2.97]$ \\
\hline Null/M1 & 20 & 11 & 0.873 & $1.07[0.44,2.49]$ & 17 & 14 & 0.774 & $1.15[0.50,2.58]$ \\
\hline Null/null & 15 & 10 & 0.492 & $1.38[0.54,3.49]$ & 14 & 11 & 0.757 & $1.15[0.46,2.84]$ \\
\hline
\end{tabular}

${ }^{\mathrm{a}}$ Reference category; $\mathrm{CI}=$ confidence level: [lower limit; upper limit]; ${ }^{\dagger} \mathrm{OR}$ was adjusted by age and sex.

The variant genotypes Ile/Val + Val/Val of GSTP1 Ile105Val were borderline associated with less frequent premalignant lesions than the wild-type Ile/Ile genotype (39.5\% versus $\left.51.8 \%, \chi^{2}(1)=4.06, p=0.051\right)$. Frequency distributions for the GSTT1 and GSTM1 null genotypes were comparable in patients with gastric atrophy/intestinal metaplasia compared with patients without premalignant lesions $(19.4 \%$ versus $22.0 \%, \chi^{2}(1)=0.28, p=0.653 ; 55.8 \%$ versus $45.4 \%$, $\chi^{2}(1)=2.93, p=0.090$, resp.).

The concomitant presence of GSTT1 and GSTM1 null genotype was similar in patients with mild or severe endoscopic lesions versus patients without lesions $(9.9 \%$ versus $\left.8.9 \%, \chi^{2}(3)=2.54, p=0.471\right)$. Analogue results were obtained for patients with gastric atrophy/intestinal metaplasia compared with patients without premalignant lesions (8.5\% versus 9.9\%, $\chi^{2}(3)=4.02, p=0.260$ ).

Compared with the wild-type Ile/Ile genotype, the variant Ile/Val + Val/Val genotypes of GSTP1 Ile105Val gene polymorphism were significantly associated with a decreased risk of gastric atrophy/intestinal metaplasia (adjusted $\mathrm{OR}=0.60$, 95\% CI: $[0.37,0.98])$ after adjusting for age and sex. We also noticed an increased risk of gastric atrophy/intestinal metaplasia for GSTM1 null genotype (adjusted OR $=1.55$, 95\% CI: $[0.96,2.53])$ with a tendency towards statistical significance $p=0.074$ (Table 2). Presence of the double null genotypes of GSTM1 and GSTT1 was borderline associated with an increased risk of premalignant lesions ( $p=0.05$, adjusted $\mathrm{OR}=1.72,95 \%$ CI: $[1.00,2.97])$.

3.3. Interaction Effect between Environmental Factors and the Selected Gene Polymorphisms on Gastric Lesions. As shown in Table 3, there was a significant interaction between the
GSTM1 polymorphism and H. pylori $(p=0.038)$. The logistic regression results (the estimation of regression coefficients is not presented) calculated a significant contribution of the GSTM1 gene polymorphism on mild or severe endoscopic lesions $(p=0.013)$ and the impact of the null gene polymorphism was different depending on $H$. pylori status (OR for interaction term $=0.31,95 \%$ CI: $[0.10,0.93]$ ). The GSTM1 null genotype was associated with an increased risk for mild or severe endoscopic lesions in patients without H. pylori $(\mathrm{OR}=2.27,95 \% \mathrm{CI}$ : $[1.20,4.37])$ while in patients with $H$. pylori infection a decreased risk was observed, without statistical significance (OR $=0.70,95 \% \mathrm{CI}$ : [0.29, 1.67]). The logistic regression results also showed a significant contribution of the GSTM1 gene polymorphism on the risk of premalignant lesions $(p=0.011)$ and the impact of the null gene polymorphism was different depending on alcohol consumption status (OR for interaction term $=0.27,95 \%$ CI: $[0.08,0.94])$. We noticed that the presence of the null genotype was associated with an increased risk odds ratio $(\mathrm{OR}=2.13,95 \% \mathrm{CI}:[1.19,3.83])$ in patients without alcohol consumption, while in patients with alcohol consumption a decreased risk was observed, without statistical significance $(\mathrm{OR}=0.58,95 \% \mathrm{CI}:[0.22,1.54])$.

The effect of the GSTT1 deleted polymorphism on premalignant lesions was different depending on drug consumption status (OR for interaction term $=0.26,95 \%$ CI: 0.07, 0.94). The GSTT1 null genotype was associated with an increased risk, without statistical significance $(\mathrm{OR}=1.82,95 \% \mathrm{CI}$ : $0.72,4.74)$ in patients without drug intake, while GSTT1 null genotype was associated with a decreased risk with no statistical significance $(\mathrm{OR}=0.47,95 \% \mathrm{CI}: 0.21,1.07)$ in patients with gastrotoxic treatments. 
TABLE 3: The gene-environment interaction in endoscopic and premalignant gastric lesions.

\begin{tabular}{|c|c|c|c|c|c|}
\hline Factors & Genotype & $\begin{array}{c}\text { Without endoscopic } \\
\text { lesions versus mild or } \\
\text { severe endoscopic lesions }\end{array}$ & $\begin{array}{l}\text { Adjusted } \mathrm{OR}^{\ddagger}[95 \% \\
\mathrm{CI}]\end{array}$ & $\begin{array}{l}\text { Without premalignant } \\
\text { lesions versus with } \\
\text { premalignant lesions }\end{array}$ & $\begin{array}{c}\text { Adjusted } \mathrm{OR}^{\ddagger}(95 \% \\
\mathrm{CI})\end{array}$ \\
\hline H. pylori & GSTP1 Ile105Val & & & & \\
\hline \multirow{2}{*}{ Negative } & Ile/Ile & $56 / 40$ & 1 (reference) & $44 / 52$ & 1 (reference) \\
\hline & $\mathrm{Ile} / \mathrm{Val}+\mathrm{Val} / \mathrm{Val}$ & $63 / 26$ & $0.55[0.29,1.04]$ & $55 / 34$ & $0.47[0.26,0.87]$ \\
\hline \multirow{3}{*}{ Positive } & Ile/Ile & $29 / 21$ & $1.00[0.48,2.07]$ & $24 / 26$ & $0.86[0.42,1.77]$ \\
\hline & $\mathrm{Ile} / \mathrm{Val}+\mathrm{Val} / \mathrm{Val}$ & $21 / 14$ & $0.70[0.32,1.54]$ & $18 / 17$ & $0.56[0.26,1.22]$ \\
\hline & & \multicolumn{2}{|c|}{$p$ value for interaction $=0.676$} & \multicolumn{2}{|c|}{$p$ value for interaction $=0.568$} \\
\hline H. pylori & GSTT1 & & & & \\
\hline \multirow{2}{*}{ Negative } & $\mathrm{T} 1$ & $96 / 49$ & 1 (reference) & $77 / 68$ & 1 (reference) \\
\hline & Null & $23 / 17$ & $1.40[0.65,2.98]$ & $22 / 18$ & $1.00[0.47,2.12]$ \\
\hline \multirow{3}{*}{ Positive } & $\mathrm{T} 1$ & $38 / 31$ & $1.39[0.75,2.57]$ & $33 / 36$ & $1.06[0.58,1.57]$ \\
\hline & Null & $12 / 4$ & $0.53[0.16,1.73]$ & $9 / 7$ & $0.71[0.25,2.01]$ \\
\hline & & \multicolumn{2}{|c|}{$p$ value for interaction $=0.087$} & \multicolumn{2}{|c|}{$p$ value for interaction $=0.576$} \\
\hline H. pylori & GSTM1 & & & & \\
\hline \multirow{2}{*}{ Negative } & M1 & $69 / 26$ & 1 (reference) & 56.39 & 1 (reference) \\
\hline & Null & $50 / 40$ & $2.23[1.20,4.37]$ & $43 / 47$ & $1.66[0.90,3.07]$ \\
\hline \multirow{3}{*}{ Positive } & M1 & $21 / 18$ & $2.07[0.92,4.69]$ & $21 / 18$ & $1.04[0.47,2.30]$ \\
\hline & Null & $29 / 17$ & $1.46[0.69,3.09]$ & $21 / 25$ & $1.57[0.77,3.19]$ \\
\hline & & \multicolumn{2}{|c|}{$p$ value for interaction $=\mathbf{0 . 0 3 8}$} & \multicolumn{2}{|c|}{$p$ value for interaction $=0.858$} \\
\hline Alcohol $^{\mathrm{a}}$ & GSTP1 Ile105Val & & & & \\
\hline \multirow{2}{*}{ No } & Ile/Ile & $67 / 47$ & 1 (reference) & $52 / 62$ & 1 (reference) \\
\hline & $\mathrm{Ile} / \mathrm{Val}+\mathrm{Val} / \mathrm{Val}$ & $62 / 27$ & $0.60[0.32,1.11]$ & $55 / 34$ & $0.49[0.27,0.87]$ \\
\hline \multirow{3}{*}{ Yes } & Ile/Ile & $18 / 14$ & $0.78[0.32,1.90]$ & $16 / 16$ & $0.64[0.26,1.55]$ \\
\hline & $\mathrm{Ile} / \mathrm{Val}+\mathrm{Val} / \mathrm{Val}$ & $22 / 13$ & $0.44[0.20,0.96]$ & $18 / 17$ & $0.42[0.20,0.90]$ \\
\hline & & \multicolumn{2}{|c|}{$p$ value for interaction $=0.909$} & \multicolumn{2}{|c|}{$p$ value for interaction $=0.628$} \\
\hline Alcohol $^{\mathrm{a}}$ & GSTT1 & & & & \\
\hline \multirow{2}{*}{ No } & $\mathrm{T} 1$ & $104 / 63$ & 1 (reference) & $22 / 14$ & 1 (reference) \\
\hline & Null & $25 / 11$ & $0.72[0.31,1.60]$ & $85 / 82$ & $0.72[0.33,1.54]$ \\
\hline \multirow{3}{*}{ Yes } & $\mathrm{T} 1$ & $30 / 17$ & $0.59[0.25,1.35]$ & $9 / 11$ & $0.59[0.25,1.34]$ \\
\hline & Null & $10 / 10$ & $1.01[0.32,2.07]$ & $25 / 22$ & $0.85[0.34,2.16]$ \\
\hline & & \multicolumn{2}{|c|}{$p$ value for interaction $=0.214$} & \multicolumn{2}{|c|}{$p$ value for interaction $=0.328$} \\
\hline Alcohol $^{\mathrm{a}}$ & GSTM1 & & & & \\
\hline \multirow{2}{*}{ No } & M1 & $74 / 32$ & 1 (reference) & $64 / 42$ & 1 (reference) \\
\hline & Null & $55 / 42$ & $1.83[1.00,3.37]$ & $43 / 54$ & $2.13[1.19,3.83]$ \\
\hline \multirow{3}{*}{ Yes } & M1 & $16 / 12$ & $1.08[0.41,2.76]$ & $13 / 15$ & $1.40[0.54,3.67]$ \\
\hline & Null & $24 / 15$ & $0.99[0.46,2.13]$ & $21 / 18$ & $0.81[0.28,1.53]$ \\
\hline & & \multicolumn{2}{|c|}{$p$ value for interaction $=0.256$} & $p$ value for inter & tion $=\mathbf{0 . 0 4 1}$ \\
\hline Smoking $^{\mathrm{b}}$ & GSTP1 Ile105Val & & & & \\
\hline No & Ile/Ile & $78 / 58$ & 1 (reference) & $66 / 70$ & 1 (reference) \\
\hline NO & $\mathrm{Ile} / \mathrm{Val}+\mathrm{Val} / \mathrm{Val}$ & $79 / 32$ & $0.51[0.29,0.89]$ & $70 / 41$ & $0.51[0.30,0.87]$ \\
\hline Yes & Ile/Ile & $7 / 3$ & $0.76[0.15,3.17]$ & $2 / 8$ & $5.14[1.15,36.52]$ \\
\hline Yes & $\mathrm{Ile} / \mathrm{Val}+\mathrm{Val} / \mathrm{Val}$ & $5 / 8$ & $1.97[0.61,6.33]$ & $3 / 10$ & $3.46[0.91,13.13]$ \\
\hline & & $p$ value for interac & tion $=0.090$ & $p$ value for inter & tion $=0.790$ \\
\hline Smoking $^{\mathrm{b}}$ & GSTT1 & & & & \\
\hline No & $\mathrm{T} 1$ & $126 / 72$ & 1 (reference) & $107 / 91$ & 1 (reference) \\
\hline & Null & $31 / 18$ & $1.06[0.53,2.10]$ & $29 / 20$ & $0.94[0.48,1.82]$ \\
\hline
\end{tabular}


TABLE 3: Continued.

\begin{tabular}{|c|c|c|c|c|c|}
\hline Factors & Genotype & $\begin{array}{c}\text { Without endoscopic } \\
\text { lesions versus mild or } \\
\text { severe endoscopic lesions }\end{array}$ & $\begin{array}{l}\text { Adjusted } \mathrm{OR}^{\ddagger}[95 \% \\
\mathrm{CI}]\end{array}$ & $\begin{array}{l}\text { Without premalignant } \\
\text { lesions versus with } \\
\text { premalignant lesions }\end{array}$ & $\begin{array}{c}\text { Adjusted } \mathrm{OR}^{\ddagger}(95 \% \\
\mathrm{CI})\end{array}$ \\
\hline \multirow{3}{*}{ Yes } & $\mathrm{T} 1$ & $8 / 8$ & $2.23[0.70,7.14]$ & $3 / 13$ & $7.36[2.04,35.67]$ \\
\hline & Null & $4 / 3$ & $1.21[0.26,5.56]$ & $2 / 5$ & $3.87[0.73,20.43]$ \\
\hline & & \multicolumn{2}{|c|}{$p$ value for interaction $=0.503$} & \multicolumn{2}{|c|}{$p$ value for interaction $=0.609$} \\
\hline Smoking ${ }^{\mathrm{b}}$ & GSTM1 & & & & \\
\hline \multirow{2}{*}{ No } & M1 & $87 / 40$ & 1 (reference) & $76 / 51$ & 1 (reference) \\
\hline & Null & $70 / 50$ & $1.68[0.97,2.93]$ & $60 / 60$ & $1.67[0.99,2.85]$ \\
\hline \multirow{3}{*}{ Yes } & M1 & $3 / 4$ & $3.69[0.71,21.11]$ & $1 / 6$ & $11.08[1.68,220.49]$ \\
\hline & Null & $9 / 7$ & $2.17[0.75,6.24]$ & $4 / 12$ & $7.96[2.43,26.06]$ \\
\hline & & \multicolumn{2}{|c|}{$p$ value for interaction $=0.294$} & \multicolumn{2}{|c|}{$p$ value for interaction $=0.509$} \\
\hline Drugs $^{c}$ & GSTP1 Ile105Val & & & & \\
\hline \multirow{2}{*}{ No } & Ile/Ile & $46 / 25$ & 1 (reference) & $31 / 40$ & 1 (reference) \\
\hline & $\mathrm{Ile} / \mathrm{Val}+\mathrm{Val} / \mathrm{Val}$ & $43 / 12$ & $0.46[0.19,1.05]$ & $33 / 22$ & $0.42[0.19,0.89]$ \\
\hline \multirow{3}{*}{ Yes } & Ile/Ile & $39 / 36$ & $1.67[0.85,3.34]$ & $37 / 38$ & $0.79[0.40,1.55]$ \\
\hline & $\mathrm{Ile} / \mathrm{Val}+\mathrm{Val} / \mathrm{Val}$ & $41 / 28$ & $1.18[0.60,2.34]$ & $40 / 29$ & $0.50[0.26,0.98]$ \\
\hline & & \multicolumn{2}{|c|}{$p$ value for interaction $=0.439$} & \multicolumn{2}{|c|}{$p$ value for interaction $=0.434$} \\
\hline Drugs $^{c}$ & GSTT1 & & & & \\
\hline \multirow{2}{*}{ No } & $\mathrm{T} 1$ & $74 / 28$ & 1 (reference) & $54 / 48$ & 1 (reference) \\
\hline & Null & $15 / 9$ & $1.65[0.61,4.26]$ & $10 / 14$ & $1.82[0.72,4.74]$ \\
\hline \multirow{3}{*}{ Yes } & $\mathrm{T} 1$ & $60 / 52$ & $2.41[1.33,4.42]$ & $56 / 56$ & $1.23[0.70,2.18]$ \\
\hline & Null & $20 / 12$ & $1.59[0.69,3.67]$ & $21 / 11$ & $0.58[0.25,1.33]$ \\
\hline & & \multicolumn{2}{|c|}{$p$ value for interaction $=0.163$} & \multicolumn{2}{|c|}{$p$ value for interaction $=\mathbf{0 . 0 4 2}$} \\
\hline $\operatorname{Drugs}^{c}$ & GSTM1 & & & & \\
\hline \multirow{2}{*}{ No } & M1 & $48 / 19$ & 1 (reference) & $36 / 31$ & 1 (reference) \\
\hline & Null & $41 / 89$ & $1.23[0.55,2.74]$ & $28 / 31$ & $1.49[0.71,3.16]$ \\
\hline \multirow{3}{*}{ Yes } & M1 & $42 / 25$ & $1.61[0.76,3.45]$ & $41 / 26$ & $0.88[0.43,1.80]$ \\
\hline & Null & $38 / 39$ & $2.95[1.47,5.91]$ & $36 / 41$ & $1.51[0.78,2.91]$ \\
\hline & & \multicolumn{2}{|c|}{$p$ value for interaction $=0.457$} & \multicolumn{2}{|c|}{$p$ value for interaction $=0.782$} \\
\hline
\end{tabular}

${ }^{\mathrm{a}}>10$ units/week; ${ }^{\mathrm{b}}>5$ cigarettes/day including during the past 5 years; ${ }^{c}$ presence of NSAIDs or antiplatelet therapy; ${ }^{\ddagger}$ OR was adjusted by age, sex, $H$. pylori, smoking, alcohol, and NSAIDs or antiplatelet therapy.

The plausible interaction effects justified the estimation of adjusted multivariable OR (Table 3 ) for the highlighted the magnitude of association.

\section{Discussions}

The most commonly deleted polymorphisms in the GSTT1 and GSTM1 genes associated with decreased detoxifying activity of the GST enzyme $[4,9]$ were extensively studied for gastric cancer occurrence and less frequently for premalignant lesions. On the other hand, the SNP in GSTP1 gene resulting in amino acid substitutions at codon 105 (Ile $\rightarrow$ Val) is also associated with reduced detoxifying activity of the GST enzyme and cancer risk but less studied in premalignant gastric lesions. Many studies showed that the polymorphic variants of GSTT1, GSTM1, and GSTP1 genes were associated with increased risk for gastric cancer, especially in the Asian population [13, 21-23]. However, certain studies performed in the European population sustained that the GST gene polymorphisms are not relevant in gastric cancer [15]. There is a paucity of information regarding the frequency and role of the mentioned polymorphism in gastric diseases in the Romanian population, characterized by a high prevalence of $H$. pylori infection and a high mortality related to gastric cancer [24], like in some Asian populations, but with a genetic European background.

The majority of previous studies sustained a decreased GST enzyme activity in the presence of $H$. pylori infection $[25,26]$. As the variant genotype of GSTP1 Ile105Val or null GSTM1 or GSTT1 genotypes were also reported to decrease the activity of the GST enzyme $[8-11,16]$, we investigated the possible interplay between GST gene polymorphisms and $H$. pylori infection in endoscopic and histologic gastric lesions. We questioned also the interplay between GST gene polymorphisms and the rest of environmental risk factors known to increase the susceptibility for endoscopic/histologic gastric lesions (gastrotoxic medication, smoking, and alcohol consumption). 
The frequency of GSTM1 null genotype was reported to range between 40 and $60 \%$ in the European population, as in our study (49.6\%), while GSTT1 null genotype was reported between $13-26 \%[15,27]$, similar to our results $(20.7 \%)$. There are wide ethnic differences in the frequency of GSTP1 Ile105Val polymorphism, ranging from a frequency between 38 and $60 \%$ of GSTP1 Ile/Val or Val/Val genotype in the European population to $15.2-61.5 \%$ in the Asian population $[19,28]$ and $45.9 \%$ in our study. The prevalence of premalignant gastric lesions in our studied population was $47.7 \%$, intermediate in comparison with worldwide reported data, correlated with the regional prevalence of $H$. pylori infection, germ virulence, or host characteristics, but very high for the European region $[29,30]$.

The GSTM1 null genotype tended to increase the risk for gastric atrophy/intestinal metaplasia, but this influence was surprisingly modified by alcohol consumption in our studied population. On the other hand, the GSTM1 null genotype in the $H$. pylori-negative patients was associated with an increased risk for severe endoscopic lesions. Our surprising findings suggest a more complex gene-environment interaction in our population, proposing an independent role of the GSTM1 deleted polymorphism for non- $H$. pylori endoscopic gastric lesions and premalignant gastric lesions. Our results are not similar with Chinese studies that failed to sustain role of GSTM1 null genotype in premalignant gastric lesions, even in association with environmental factors [31]. Current observations sustain the possible role of GSTM1 polymorphism in gastric diseases in our population, as a recent meta-analysis also proved its role in carcinogenesis in Caucasian population modulated by $\mathrm{H}$. pylori infection and smoking [32].

The GSTT1 null genotype seems to have no influence on endoscopic or premalignant gastric lesions, similar with other results in this respect [31]. Hence, in the presence of gastrotoxic drug consumption (NSAIDs and/or antiplatelet drugs) the presence of GSTT1 null genotype decreased the risk for gastric atrophy/intestinal metaplasia. The mechanisms of this association are worth to be investigated as NSAIDs and aspirin was proven to protect against the risk of gastric cancer by a different cyclooxygenase 2 mediated pathway [33-35] in order to determine genetic factors that can be used to identified candidates for preventive therapy. The combined GSTT1 T1 and GSTM1 null genotypes were correlated with an increased risk for premalignant lesions, sustaining the greater influence of the GSTM1 deleted polymorphism in our population, and the unusual effect of the GSTT1 polymorphism in gastric lesions.

The variant genotypes Ile/Val or $\mathrm{Val} / \mathrm{Val}$ of GSTP1 Ile105Val in our patients were surprisingly correlated with less frequent premalignant lesions. Despite the proved role of the variant allele Val of GSTP1 Ile105Val SNP in gastric cancer risk in some Asian populations, its role for the gastric premalignant lesions risk has been sustained only in subgroups $>60$ years or in association with $H$. pylori infection, smoking, or alcohol consumption in a Chinese study [36]. Despite the similar frequency of gastric atrophy in patients with variant GSTP1 Ile105Val genotype in Chinese and Romanian populations (37\% versus 35.7\%) [34], environmental factors did not influence the role of this gene polymorphism in premalignant gastric lesions in our study. Our results need further investigation, as numerous complex gene-environment interactions in various diseases implying the GSTP1 Ile105Val gene polymorphism were observed, with no clear mechanism [37].

The GST polymorphisms seem to play a role in gastric cancer disease in our population, modulated by exposure to various exogenous factors (smoking, alcohol, gastrotoxic drugs, and $H$. pylori), but probably with more complex genegene and gene-environment interactions than those already studied. Our results can be explained by different exposures to lifestyle risk factors and the different genetic background in various populations.

The limitations of our study were firstly the low number of cases in some subgroups used for stratified analysis, which led to relatively large $95 \%$ confidence intervals or lack of statistical significance in some cases. Secondly, we could not apply the multiplicative model for test interaction between combined genotype and environmental factors due to the low frequency of some specific classes in combined genotype GSTM1 and GSTT1. Thirdly, for H. pylori infection we used only the histologic diagnosis, which can miss certain cases with less extensive germ colonization.

The strength of our study is the prospective evaluation of the proposed genetic host factors playing a role in gastric carcinogenesis in a specific ethnic population, in association with the most important clinical and pathological aspects. To the best of our knowledge this is the first study questioning the interplay between GSTM1, GSTT1, and GSTP1 Ile105Val gene polymorphisms and environmental factors in gastric lesions in a Caucasian population.

In conclusion, the GSTM1 and GSTT1 null genotypes increased the risk for premalignant and endoscopic lesions in our population, modulated by $H$. pylori, alcohol, or gastrotoxic drug consumption, while presence of the GSTPIVal allele seemed to reduce the risk for gastric premalignant lesions.

\section{Competing Interests}

The authors declare that there is no conflict of interests regarding the publication of this paper.

\section{References}

[1] P. Correa, W. Haenszel, C. Cuello, S. Tannenbaum, and M. Archer, "A model for gastric cancer epidemiology," The Lancet, vol. 306, no. 7924, pp. 58-60, 1975.

[2] P. Correa and M. B. Piazuelo, "The gastric precancerous cascade," Journal of Digestive Diseases, vol. 13, no. 1, pp. 2-9, 2012.

[3] E. Garza-González and G. I. Pérez-Pérez, "Relevance of host factors in gastric cancer associated with Helicobacter Pylori," in Gastric Carcinoma-New Insights into Current Management, D. Lazăr, Ed., InTech, Rijeka, Croatia, 2013.

[4] J. D. Hayes and R. C. Strange, "Glutathione S-transferase polymorphisms and their biological consequences," Pharmacology, vol. 61, no. 3, pp. 154-166, 2000. 
[5] T. Tahara, T. Shibata, M. Nakamura et al., "Effect of genetic polymorphisms related to DNA repair and the xenobiotic pathway on the prognosis and survival of gastric cancer patients," Anticancer Research, vol. 31, no. 2, pp. 705-710, 2011.

[6] P. Yadav, A. Chatterjee, and A. Bhattacharjee, "Identification of deleterious nsSNPs in $\alpha, \mu, \pi$ and $\theta$ class of GST family and their influence on protein structure," Genomics Data, vol. 2, pp. 6672, 2014.

[7] J. D. Hayes and D. J. Pulford, "The glutathione S-transferase supergene family: regulation of GST and the contribution of the isoenzymes to cancer chemoprotection and drug resistance," Critical Reviews in Biochemistry and Molecular Biology, vol. 30, no. 6, pp. 445-600, 1995.

[8] F. Ali-Osman, O. Akande, G. Antoun, J.-X. Mao, and J. Buolamwini, "Molecular cloning, characterization, and expression in Escherichia coli of full-length cDNAs of three human glutathione S-transferase Pi gene variants. Evidence for differential catalytic activity of the encoded proteins," Journal of Biological Chemistry, vol. 272, no. 15, pp. 10004-10012, 1997.

[9] R. C. Strange, M. A. Spiteri, S. Ramachandran, and A. A. Fryer, "Glutathione-S-transferase family of enzymes," Mutation Research - Fundamental and Molecular Mechanisms of Mutagenesis, vol. 482, no. 1-2, pp. 21-26, 2001.

[10] G. Ginsberg, S. Smolenski, D. Hattis, K. Z. Guyton, D. O. Johns, and B. Sonawane, "Genetic polymorphism in glutathione transferases (GST): population distribution of GSTM1, T1, and P1 conjugating activity," Journal of Toxicology and Environmental Health-Part B: Critical Reviews, vol. 12, no. 5-6, pp. 389-439, 2009.

[11] P. Zimniak, B. Nanduri, S. Pikula et al., "Naturally occurring human glutathione S-transferase GSTP1-1 isoforms with isoleucine and valine in position 104 differ in enzymic properties," European Journal of Biochemistry, vol. 224, no. 3, pp. 893899, 1994.

[12] A. Hidaka, S. Sasazuki, K. Matsuo et al., "CYP1A1, GSTM1 and GSTT1 genetic polymorphisms and gastric cancer risk among Japanese: a nested case-control study within a large-scale population-based prospective study," International Journal of Cancer, vol. 139, no. 4, pp. 759-768, 2016.

[13] S. Ghatak, R. P. Yadav, F. Lalrohlui et al., "Xenobiotic Pathway Gene Polymorphisms Associated with Gastric Cancer in High Risk Mizo-Mongoloid Population, Northeast India," Helicobacter, vol. 21, no. 6, pp. 523-535, 2016.

[14] A. Haholu, U. Berber, B. Karagöz, T. Tuncel, O. Bilgi, and D. Demirel, "Is there any association of glutathione S-transferase T1 (GSTT1) and glutathione S-transferase M1 (GSTM1) gene polymorphism with gastric cancers?" Polish Journal of Pathology, vol. 64, no. 4, pp. 247-252, 2013.

[15] M. A. García-González, E. Quintero, L. Bujanda et al., "Relevance of GSTM1, GSTT1, and GSTP1 gene polymorphisms to gastric cancer susceptibility and phenotype," Mutagenesis, vol. 27, no. 6, pp. 771-777, 2012.

[16] S. Tripathi, U. Ghoshal, B. Mittal, D. Chourasia, S. Kumar, and U. C. Ghoshal, "Association between gastric mucosal glutathione-S-transferase activity, glutathione-S-transferase gene polymorphisms and Helicobacter pylori infection in gastric cancer," Indian Journal of Gastroenterology, vol. 30, no. 6, pp. 257-263, 2011.

[17] T. V. Nguyen, M. J. R. Janssen, M. G. H. Van Oijen et al., "Genetic polymorphisms in GSTA1, GSTP1, GSTT1, and GSTM1 and gastric cancer risk in a Vietnamese population," Oncology Research, vol. 18, no. 7, pp. 349-355, 2010.
[18] B. Chen, L. Cao, Y. Zhou et al., "Glutathione S-Transferase T1 (GSTT1) gene polymorphism and gastric cancer susceptibility: a meta-analysis of epidemiologic studies," Digestive Diseases and Sciences, vol. 55, no. 7, pp. 1831-1838, 2010.

[19] A. Sharma, A. Pandey, S. Sharma et al., "Genetic polymorphism of glutathione S-transferase P1 (GSTP1) in Delhi population and comparison with other global populations," Meta Gene, vol. 2, no. 1, pp. 134-142, 2014.

[20] S. Hohaus, A. Di Ruscio, A. Di Febo et al., "Glutathione Stransferase P1 genotype and prognosis in Hodgkin's lymphoma," Clinical Cancer Research, vol. 11, no. 6, pp. 2175-2179, 2005.

[21] Y. Zhao, X. Deng, G. Song, S. Qin, and Z. Liu, “The GSTM1 null genotype increased risk of gastric cancer: a meta-analysis based on 46 studies," PLoS ONE, vol. 8, no. 11, Article ID e81403, 2013.

[22] W. Ma, L. Zhuang, B. Han, and B. Tang, "Association between glutathione S-transferase T1 null genotype and gastric cancer risk: a meta-analysis of 48 studies," PLOS ONE, vol. 8, no. 4, Article ID e60833, 2013.

[23] Y. Ma, X. Wei, G. Han, M. Xue, G. Li, and Y. Li, "Glutathione Stransferase P1 Ile105Val polymorphism contributes to increased risk of gastric cancer in East Asians," Tumor Biology, vol. 34, no. 3, pp. 1737-1742, 2013.

[24] Cancer today. Fact Sheets by Population, http://gco.iarc.fr/ today $/$ fact-sheets-populations?population $=642 \&$ sex $=0 \#$ collapsel.

[25] M.-L. Verhulst, A. H. A. M. Van Oijen, H. M. J. Roelofs, W. H. M. Peters, and J. B. M. J. Jansen, "Antral glutathione concentration and glutathione S-transferase activity in patients with and without Helicobacter pylori," Digestive Diseases and Sciences, vol. 45, no. 3, pp. 629-632, 2000.

[26] W. Beil, B. Obst, K.-F. Sewing, and S. Wagner, "Helicobacter pylori reduces intracellular glutathione in gastric epithelial cells," Digestive Diseases and Sciences, vol. 45, no. 9, pp. 1769$1773,2000$.

[27] S. Garte, L. Gaspari, A. K. Alexandrie et al., "Metabolic gene polymorphism frequencies in control populations," Cancer Epidemiology, Biomarkers \& Prevention, vol. 10, pp. 1239-1248, 2001.

[28] S. S. Soya, N. Padmaja, and C. Adithan, "Genetic polymorphisms of CYP2E1 and GSTP1 in a south indian populationcomparison with North Indians, Caucasians and Chinese," Asian Pacific Journal of Cancer Prevention, vol. 6, no. 3, pp. 315319, 2005.

[29] K. Borch, K.-Å. Jõnsson, F. Petersson, S. Redéen, S. Mårdh, and L. E. Franzén, "Prevalence of gastroduodenitis and Helicobacter pylori infection in a general population sample," Digestive Diseases and Sciences, vol. 45, no. 7, pp. 1322-1329, 2000.

[30] D. Zou, J. He, X. Ma et al., "Helicobacter pylori infection and gastritis: the Systematic Investigation of gastrointestinaL diseases in China (SILC)," Journal of Gastroenterology and Hepatology, vol. 26, no. 5, pp. 908-915, 2011.

[31] W.-C. You, J.-Y. Hong, L. Zhang et al., “Genetic polymorphisms of CYP2E1, GSTT1, GSTP1, GSTM1, ALDH2, and ODC and the risk of advanced precancerous gastric lesions in a Chinese population," Cancer Epidemiology Biomarkers and Prevention, vol. 14, no. 2, pp. 451-458, 2005.

[32] X. Lao, Q. Peng, Y. Lu et al., "Glutathione S-transferase gene GSTM1, gene-gene interaction, and gastric cancer susceptibility: evidence from an updated meta-analysis," Cancer Cell International, vol. 14, no. 1, 2014. 
[33] W.-K. Huang, H.-T. Tu, and L.-C. See, "Aspirin use on incidence and mortality of gastrointestinal cancers: current state of epidemiological evidence," Current Pharmaceutical Design, vol. 21, no. 35, pp. 5108-5115, 2015.

[34] Y. Zhang, K.-F. Pan, L. Zhang et al., "Helicobacter pylori, cyclooxygenase- 2 and evolution of gastric lesions: results from an intervention trial in China," Carcinogenesis, vol. 36, no. 12, pp. 1572-1579, 2015.

[35] Y. Shao, K. Sun, W. Xu, X.-L. Li, H. Shen, and W.-H. Sun, "Helicobacter pylori infection, gastrin and cyclooxygenase- 2 in gastric carcinogenesis," World Journal of Gastroenterology, vol. 20, no. 36, pp. 12860-12873, 2014.

[36] Y. Zhang, L.-P. Sun, C.-Z. Xing et al., "Interaction between GSTP1 Val allele and H. pylori infection, smoking and alcohol consumption and risk of gastric cancer among the Chinese population," PLoS ONE, vol. 7, no. 10, Article ID e47178, 2012.

[37] A. L. Hollman, P. B. Tchounwou, and H. C. Huang, “The association between gene-environment interactions and diseases involving the human GST superfamily with SNP Variants," International Journal of Environmental Research and Public Health, vol. 13, no. 4, p. 379, 2016. 


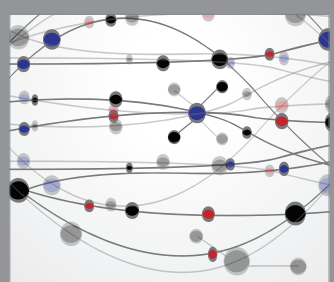

The Scientific World Journal
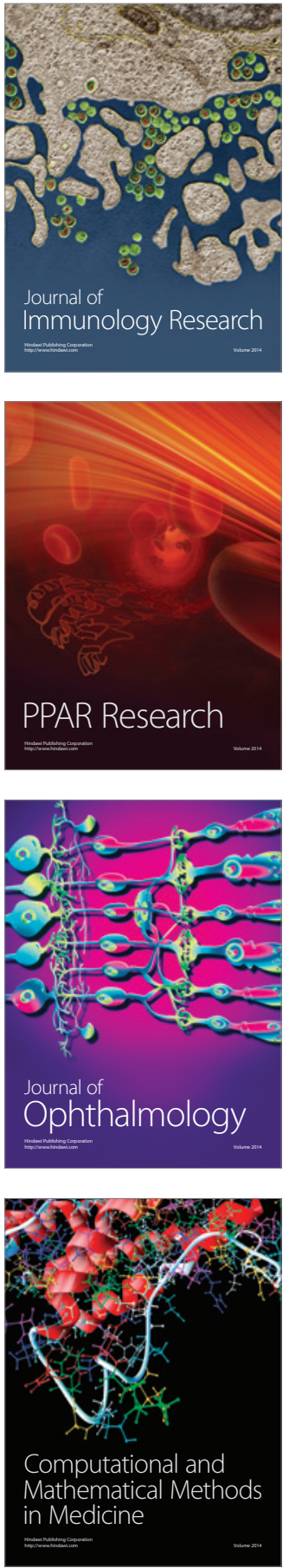

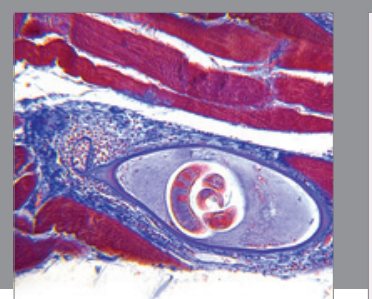

Gastroenterology Research and Practice
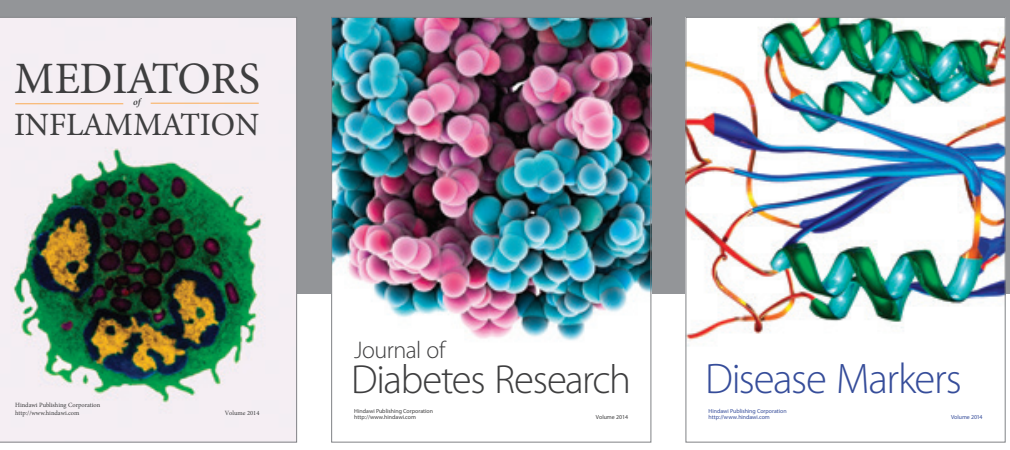

Disease Markers

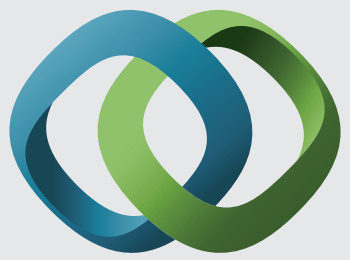

\section{Hindawi}

Submit your manuscripts at

https://www.hindawi.com
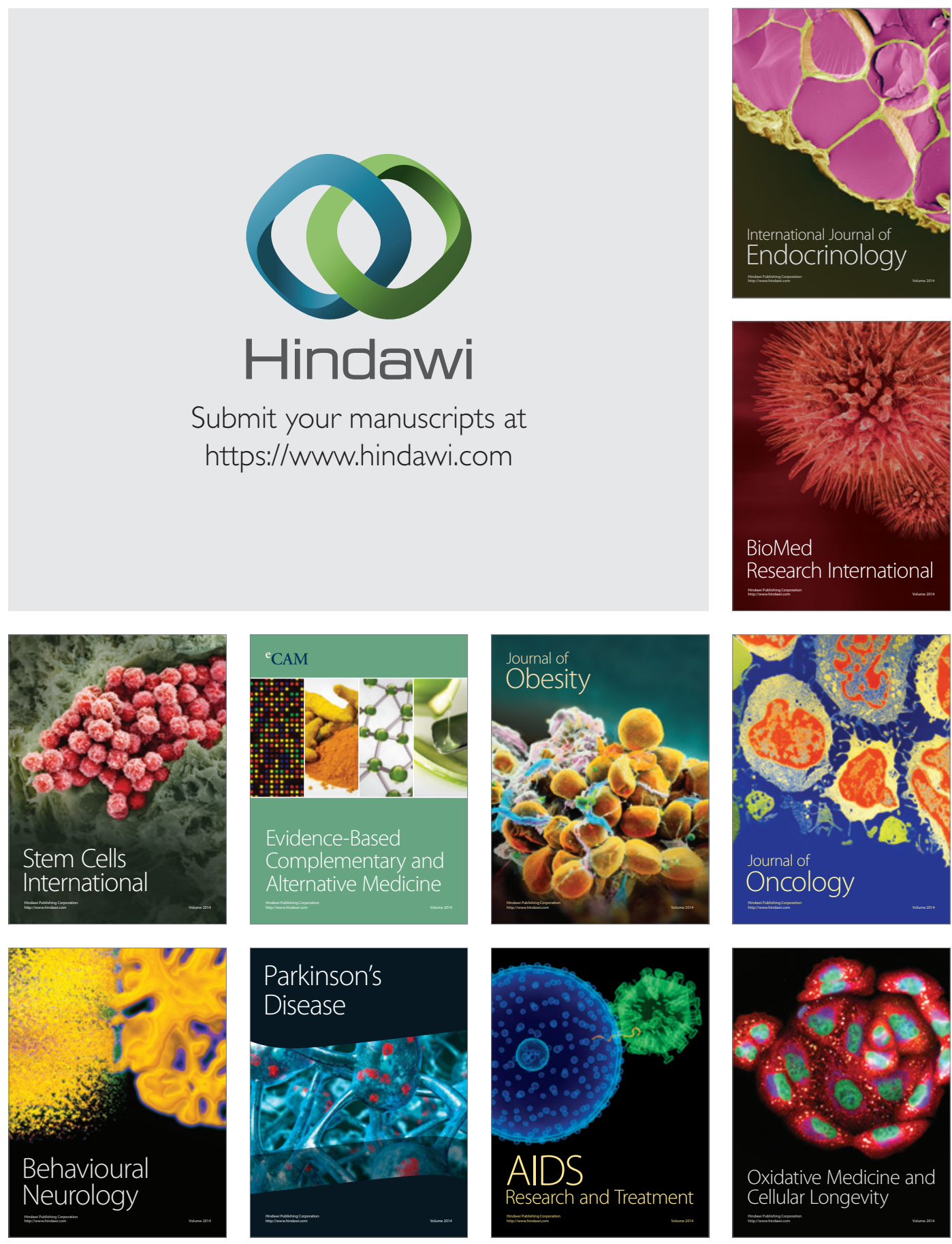